\title{
DEVELOPING THE ROLES OF PARENTS' COUNCILS IN SCHOOLS IN THE SULTANATE OF OMAN IN THE LIGHT OF THE FOURTH INDUSTRIAL REVOLUTION
}

http://dx.doi.org/10.47832/2757-5403.4-3.26

\author{
Khamis Abdullah Said AL BUSAIDI' ${ }^{1}$, Salim Humaid Rashid AL BADAI² \& Rahma Nasir Salim AL SAADI
}

\begin{abstract}
:
This study aim to identify the roles of student's parents' councils, and examine the possibility of developing them by reviewing international experiences in this field, and benefiting from the outputs of the fourth industrial revolution in the education sector. The study also focus on the actual role of parents' councils in schools in the Sultanate, and the efforts made to achieve partnership with society, and developing the regulations governing these councils, to keep pace with global scientific developments which depend on granting broad powers to these councils in order to be able to perform their work more effectively and with broader independence, and one of the most prominent recommendations that came out of this study is the need to carefully select the members of parents councils according to A specific mechanism that ensures the selection of the active members in society, developing the roles of parents' councils by expanding the powers granted to them, increasing the awareness of school staff, and making the council members aware of the importance of partnership in the areas of joint cooperation between them, which include (vision, goals, planning, managing financial resources, etc.), and the necessity of holding programs And training courses for members of student parents' councils, and school staff, on the requirements for developing the roles of these councils in the light of the Fourth Industrial Revolution, and developing programs and methods for teacher preparation in higher education institutions, in line with the requirements of the Fourth Industrial Revolution, and the Ministry of Education adopting a national strategy aimed at Designing educational and training programs that are compatible with the nature of the next stage, and the needs of the labor market in light of the Fourth Industrial Revolution.
\end{abstract}

\footnotetext{
${ }^{1}$ Dr. , Ministry of Education, Sultanate of Oman, khamisalbu@gmail.com, https://orcid.org/0000-0002-2420$\frac{9402}{2}$

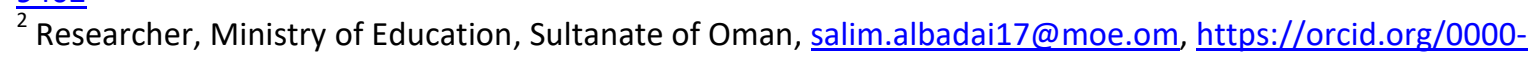
0002-7100-9294

${ }^{3}$ Researcher, Ministry of Education, Sultanate of Oman, rahma.alsaadi@moe.om, https://orcid.org/0000-0003$\underline{1159-0221}$
}

Copyright (C) Published by IJHER Journal, www.ijherjournal.com Rimar Academy, Fatih, Istanbul, 34093 Turkey

All rights reserved 
Key words: Student Parents' Councils, The Fourth Industrial Revolution.

\title{
تطوير أدوار مجالس أولياء أمور الطلبة في مدارس سلطنة عمان في ضوء الثورة الصناعية الرابعة ملإنة
}

4

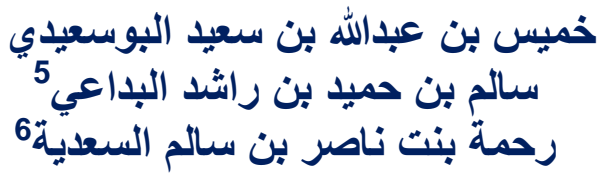

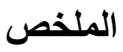

هدفت الدراسة إلى التعرف على أدوار مجالس أولياء أمور الطلبة، وبحث إمكانية تطويرها

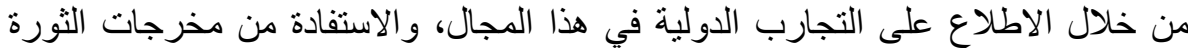

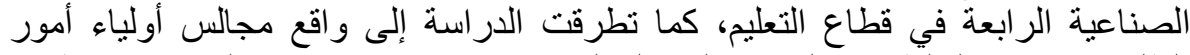

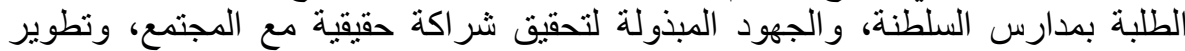

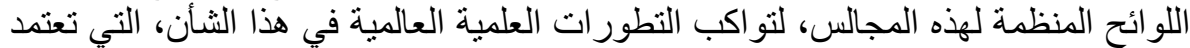

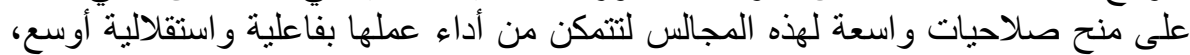

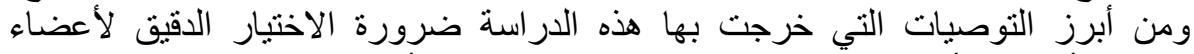

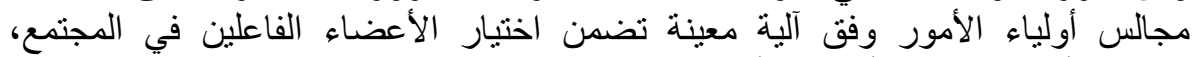

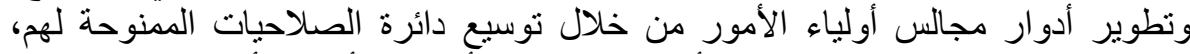

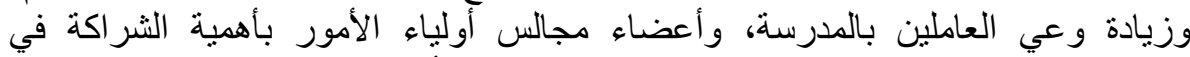

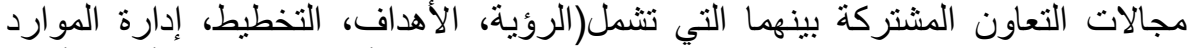

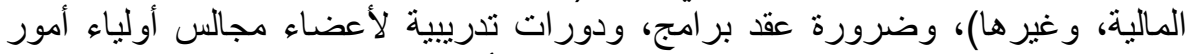

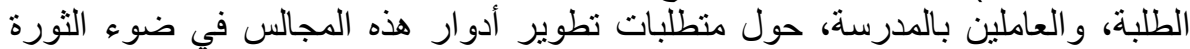

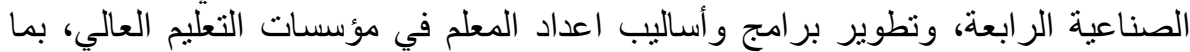

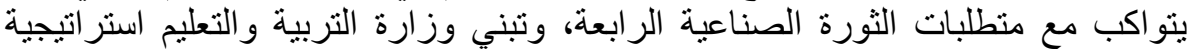

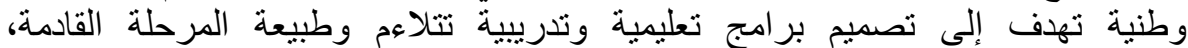
واحتياجات سوق العمل في ظل الثورة الصناعية الرابعة.

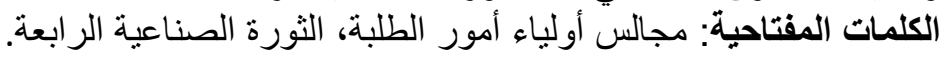

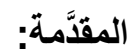

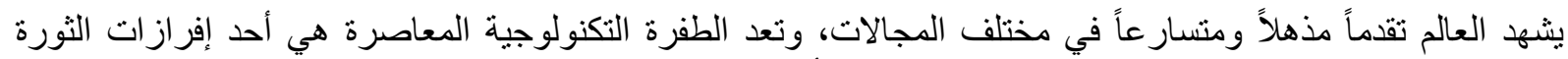

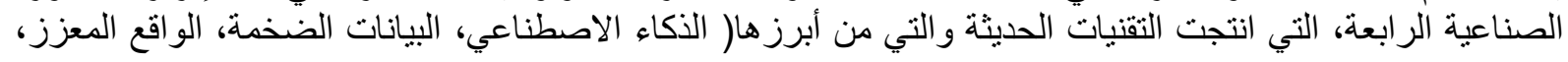




\section{DEVELOPING THE ROLES OF PARENTS' COUNCILS IN SCHOOLS IN THE \\ SULTANATE OF OMAN IN THE LIGHT OF THE FOURTH INDUSTRIAL \\ REVOLUTION}

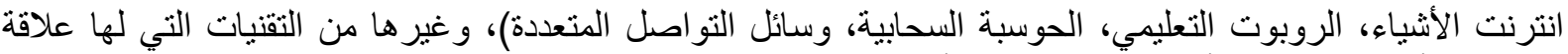

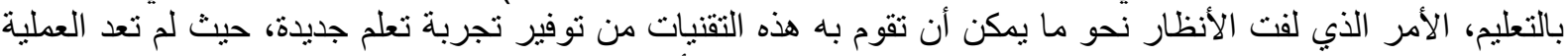

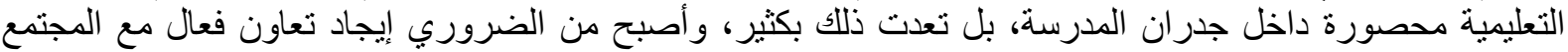

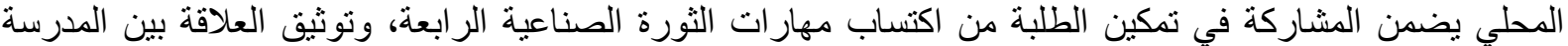

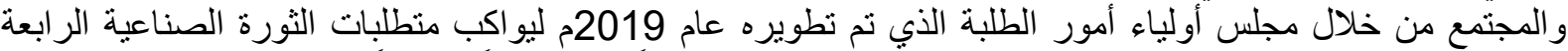

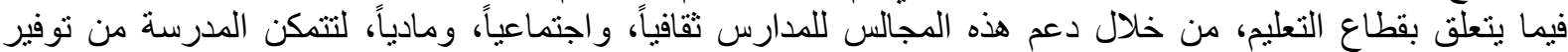

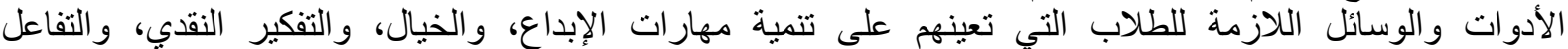
الاجتماعي، و البر اعة البدنية، و غير ها من المهار التهات.

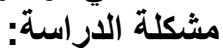

اهتمت وزارة التربية والتعليم بالتحديث والتقويم التيمة المستمر للوائح المنظمة لعمل مجالس أولياء الأمور بما يخدم العملية

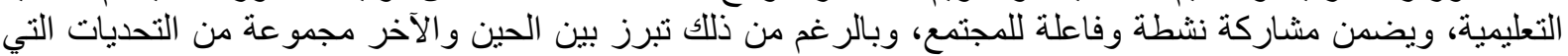

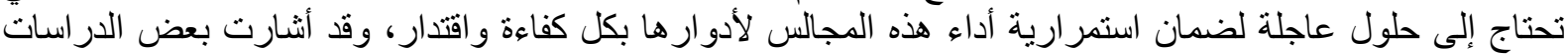

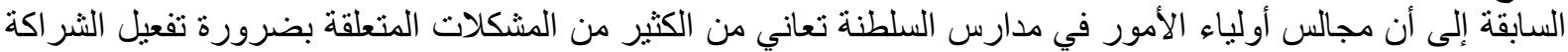

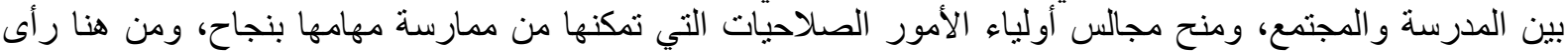

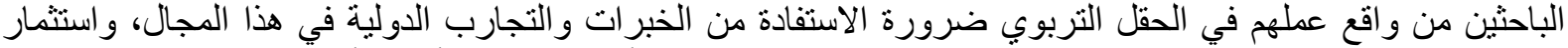
مخرجات الثورة الصناعية الر ابعة في تطوير التعليم، وضمان مشاركة أوسع لمجالس أولياء أمور الطلبة بمدارس التعليم التئ العام بسلطنة عمان.

وتأسيساً على ما سبق يمكن أن تتحدد مشكلة الدراسة في التساؤ لات التالية:

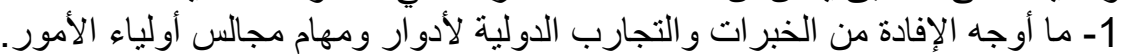

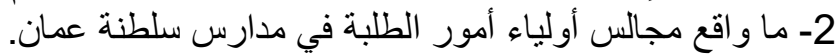

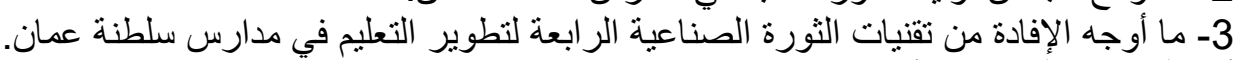

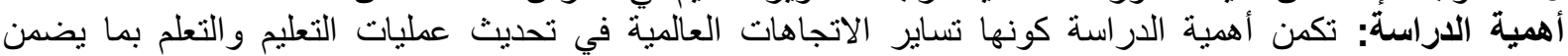

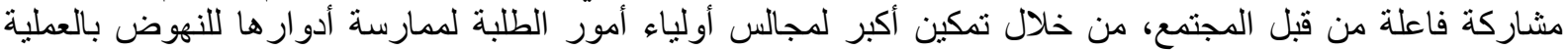

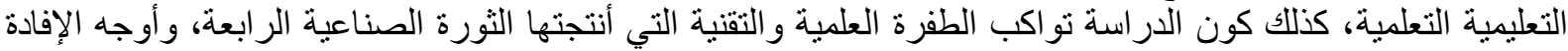
منها على قطاع التعليم في السلطنة.

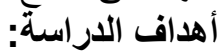

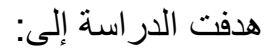
1- التعرف على أوجه الإفادة من الخبرات والتجارب الدولية لأدو ار ومهام مجالس أولياء الأمور .

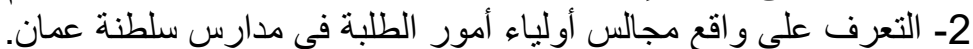
3- التعرف على أوجه الإفادة من ثقنيات الثورة الصناه الطناعية الر ابعة لتطوير التعليم في مدارس سلطنة عمان. منهج الاراسة:

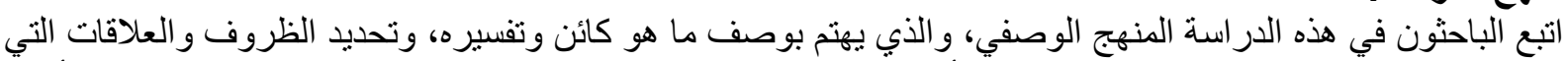

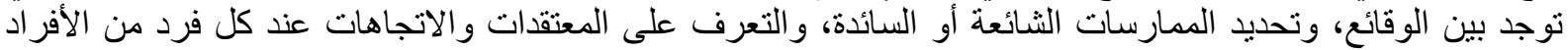
و الجماعات وطر ائقها في النمو و التطور (مازن، 2012). حدود الاراسة: تمثلت حدود الدر اسة في الآتي:

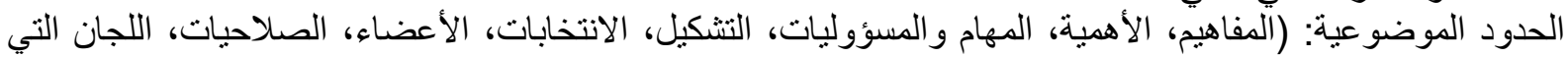
تتبع هذه المجالس). الحدود البشرية: حيث اقتصرت القدرت على أعضاء مجالس أولباء أمور الطلبة بسلطنة عمان.

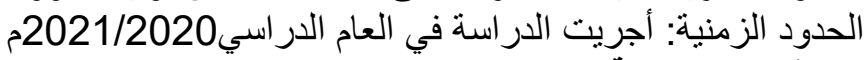
مصطلحات الاراسة:

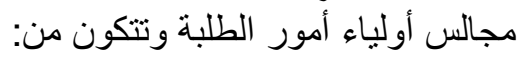

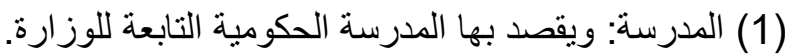
(2) مجلس المدرسة: مجلس أولياء الأمور بالمدرسة. (3) مجلس الولاية: مجلس أولياء الأمور بالولية لألاية.

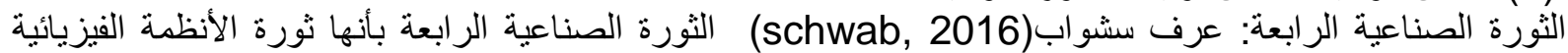
السيير انية أي عصر الاتصالات العالمية وثورة الانترنت، حيث أن سرعة التقدم التكنولوجي ليس له سابقة تاريخية في 
ربطها للمليار ات من الناس من خلال الأجهزة المحمولة التي لديها طاقة معالجة غير مسبوقة، وتخزين، ووصول غير محدود للمعرفة.

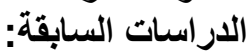
قام الباحثين بتقسيم الدراسات السابقة إلى قسمين: القسم الأول بتعلق بالدراسات الخاصة بتطوير مجالئ بالس أولياء الأمور،

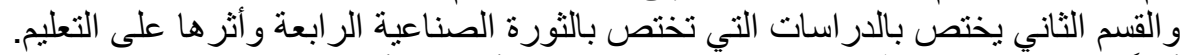
أولاً: الاراسات السابقة التي تتعلق بتطوير مجالس أولياء الأمور: دراسة عاشور (2010): هدفت الدراسة إلى التعرف على على دور مدير المدرسة في تفعيل الثر اكة بين المدرسة و المجتمع المحلي في سلطنة عمان،

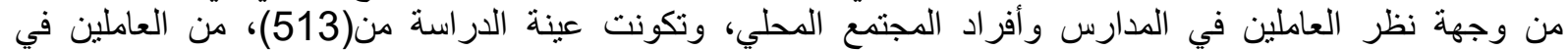

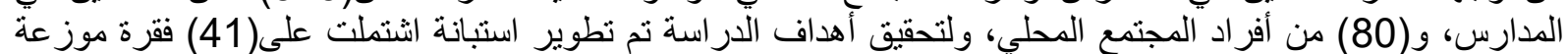

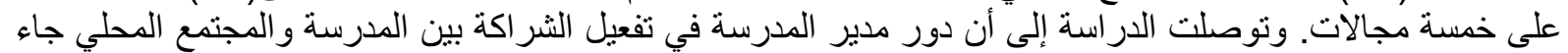

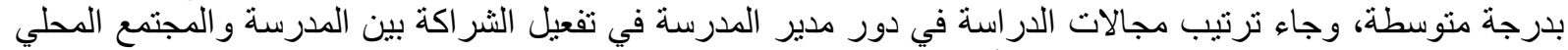

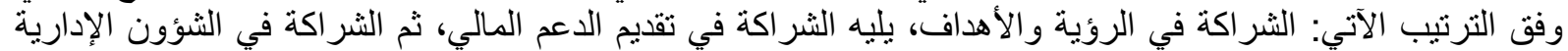

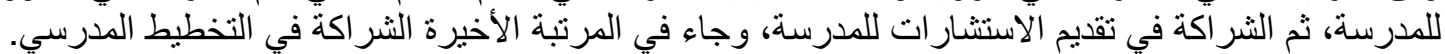

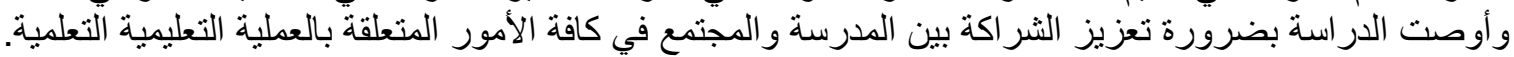
دراسة زامل (2013): مارست

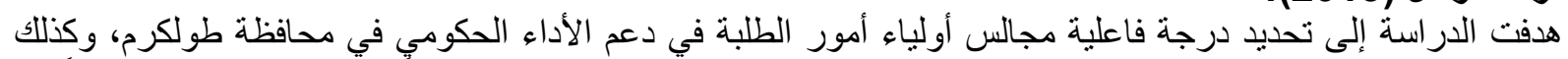

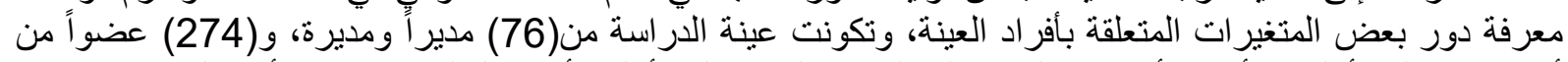

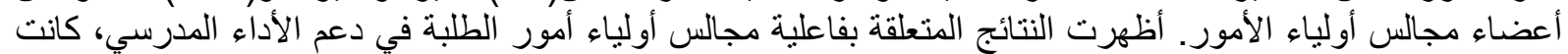

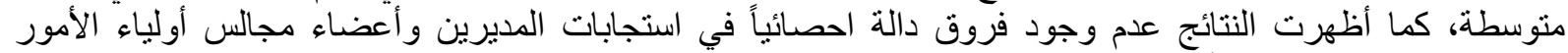

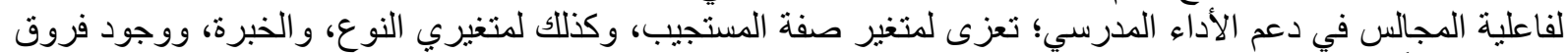
دالة إحصائياً في متغير المؤهل الأل العلمي.

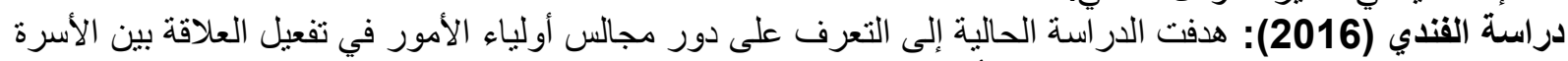

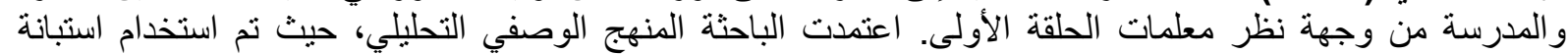

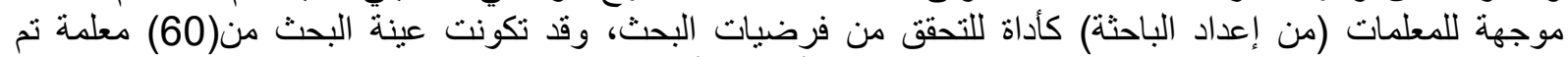

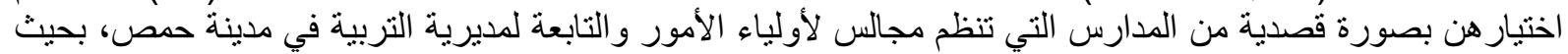

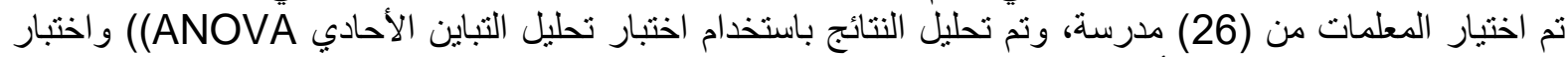

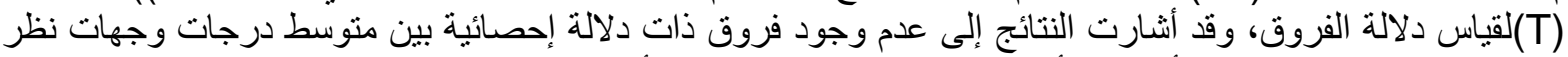

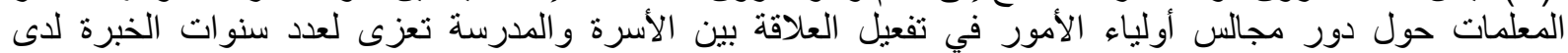

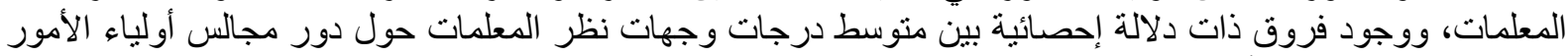

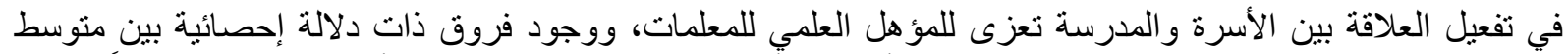

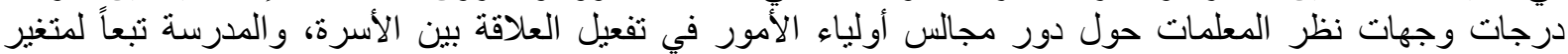

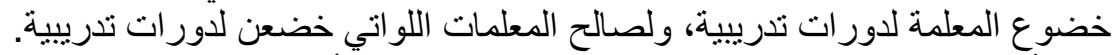

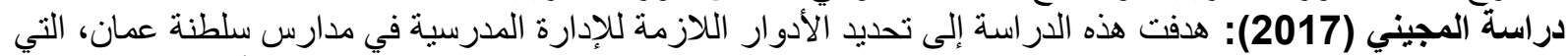

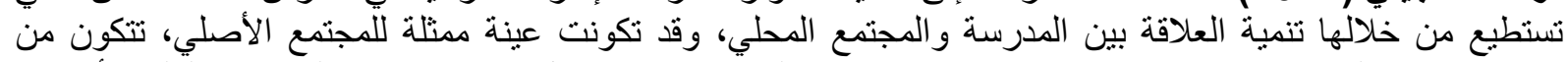

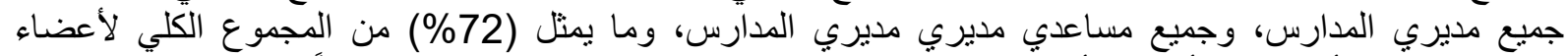

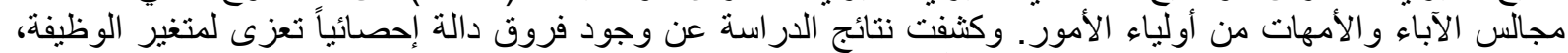

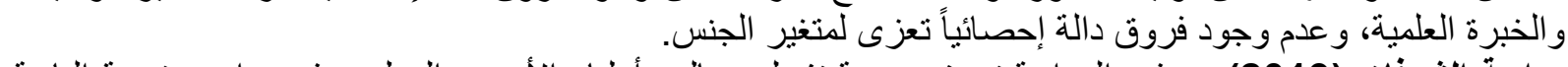

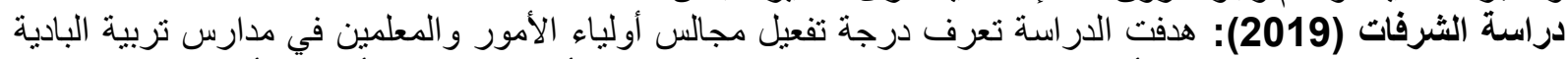

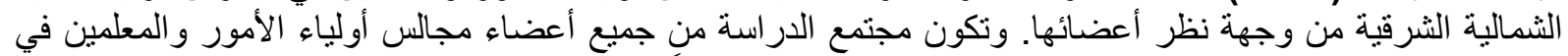

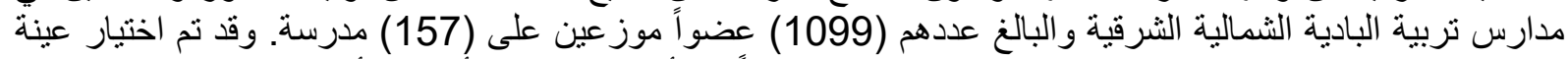

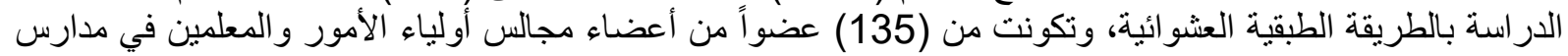

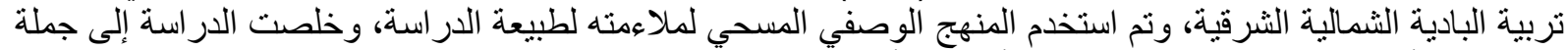

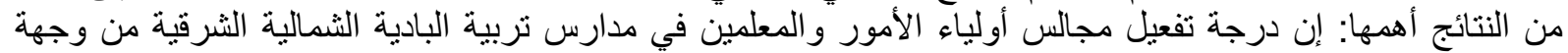

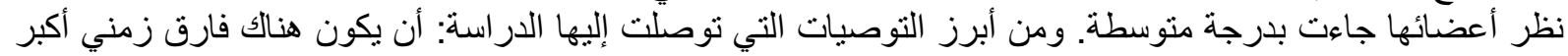

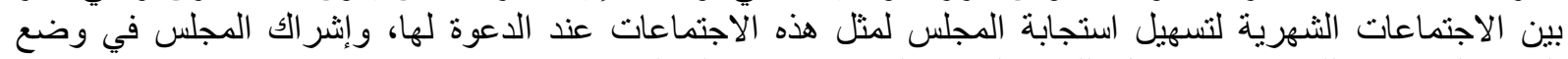

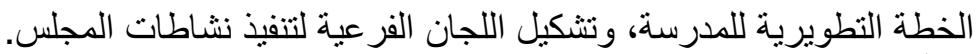
ثنانياً: الاراسات السابقة التي تتعلق بالثورة الصناعية الرابعة وأثر ها على التعليم: 


\section{DEVELOPING THE ROLES OF PARENTS' COUNCILS IN SCHOOLS IN THE SULTANATE OF OMAN IN THE LIGHT OF THE FOURTH INDUSTRIAL REVOLUTION}

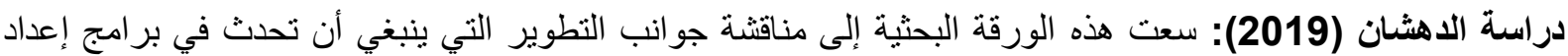

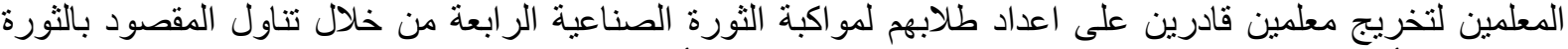

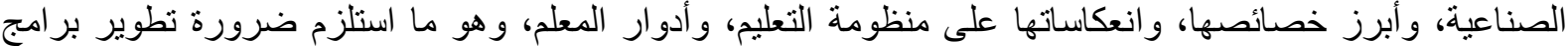

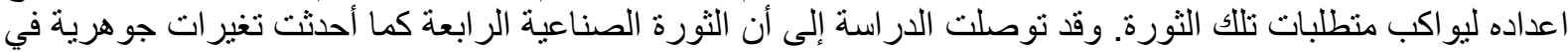

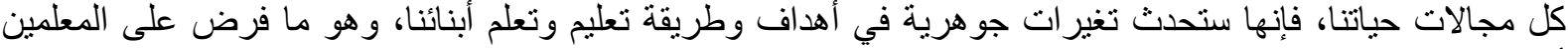

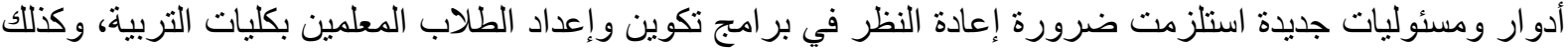

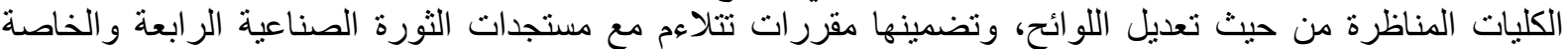

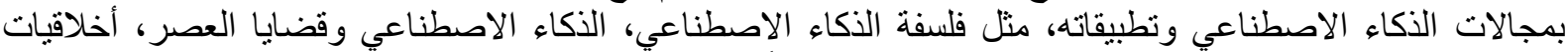

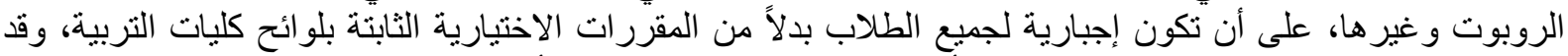

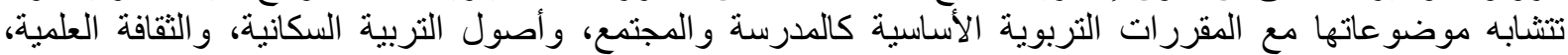

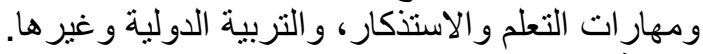

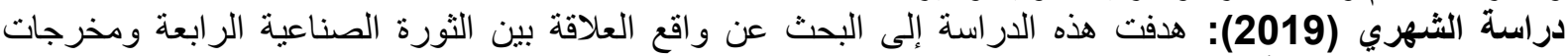

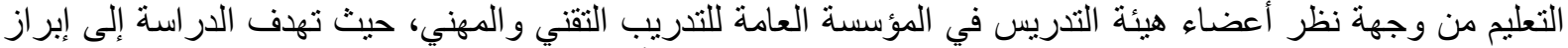

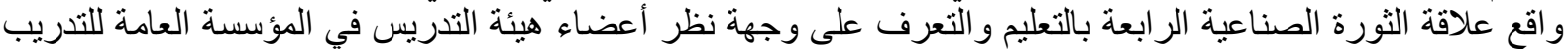

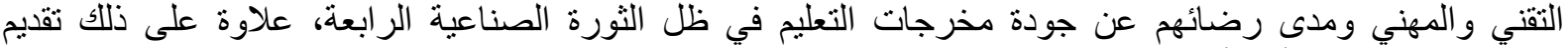

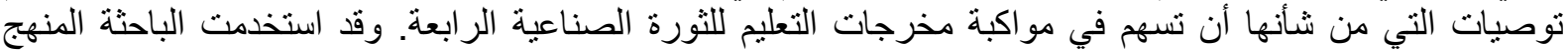

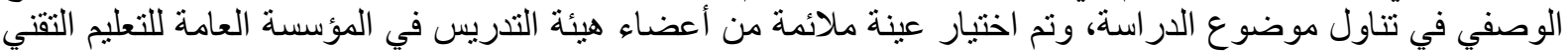

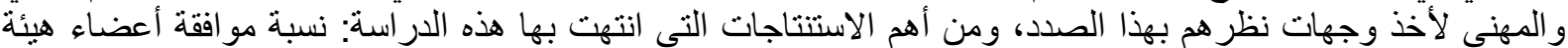

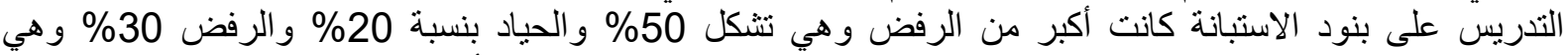

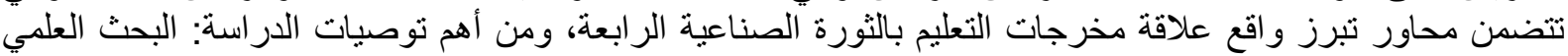

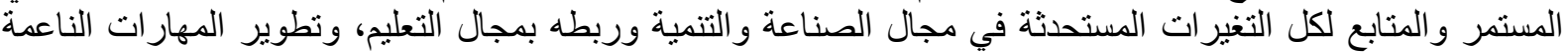

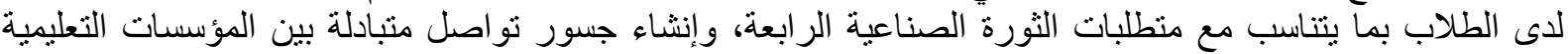

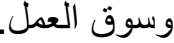
دراسة العميري (2020): انصب التئمام هذه الدراسة في الكثف عن سبل توظيف تطبيقات الثورة الصناعية الرابعة في

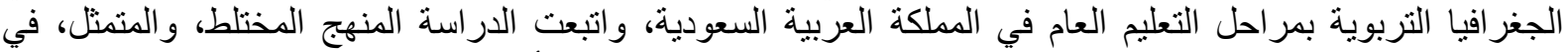

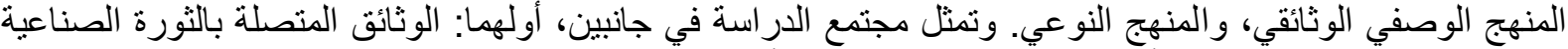

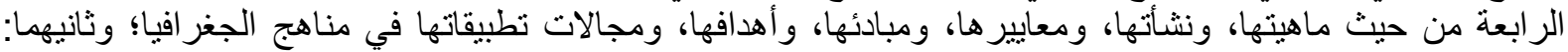

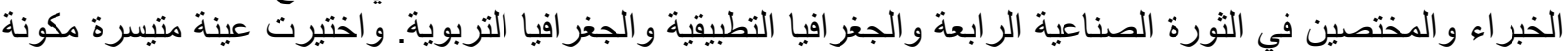

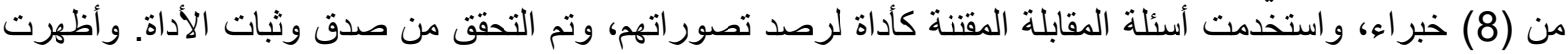

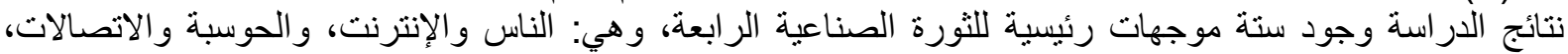

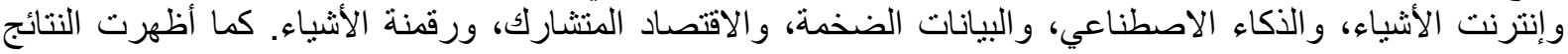

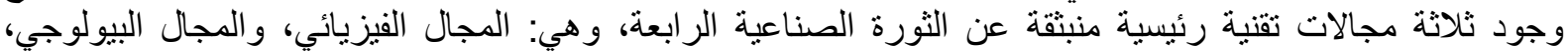

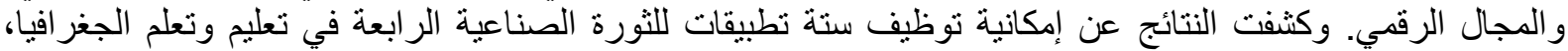

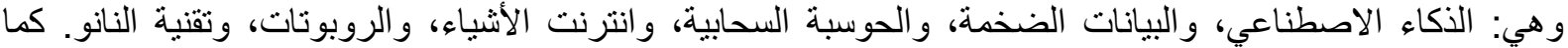

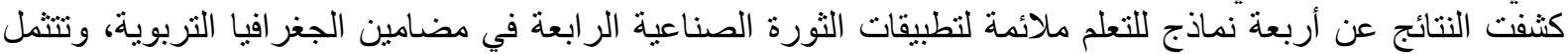

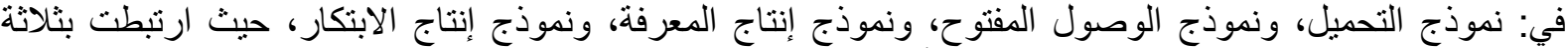

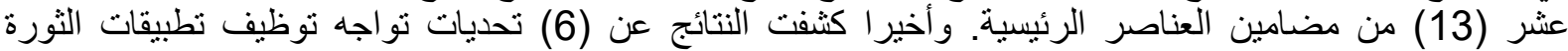

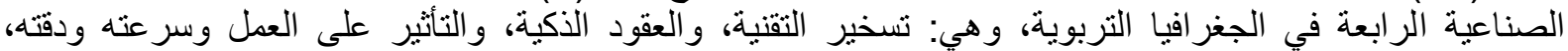
وخلخلة الطبقة الاجتماعية الوسطى، وسيطرة العملاء، وتطوير المهن. وفي الختام قدمت مجموعة من التوبية التوصيات و والمقترحات المناسبة للار اسة. دراسة الذبياني (2020): تهدف الدراسة السة الحالية إلى نطوير مؤسسات التعليم الجامعي بالمملكة العربية السعودية في ضوء متطلبات الثورة الصناعية الرابعة، ولتحقيق هذا الهدف فقد تم استخدام المنهج الوصفي، التئية تم الاستعانة بأحد مداخل

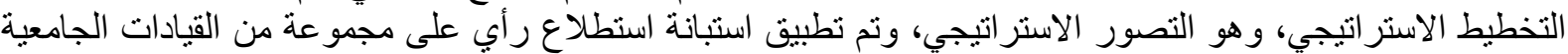

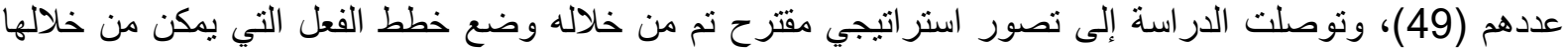

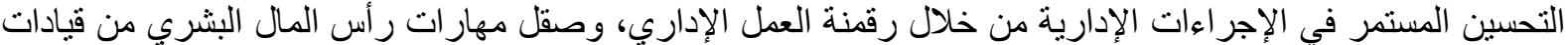

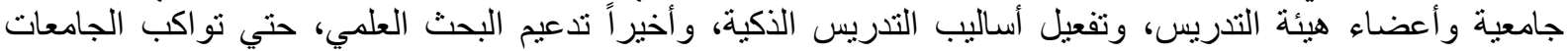


من خلال استعر اض الدراسات السابقة في محوري الدراسة نجد أن الدراسة الحالية ومن خلال المحور الأول المتعلق الماتق

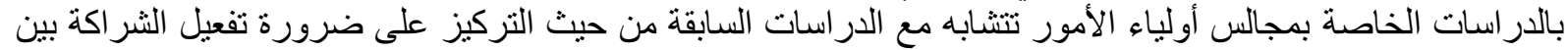

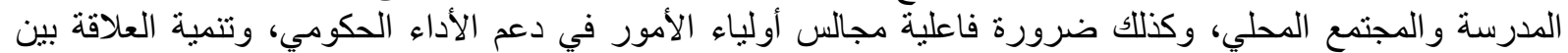
المدرسة والمجتمع؛ لضمان مشاركة أوسع من هذه المجالس المالس في العملية التعليميّة التعلمية.

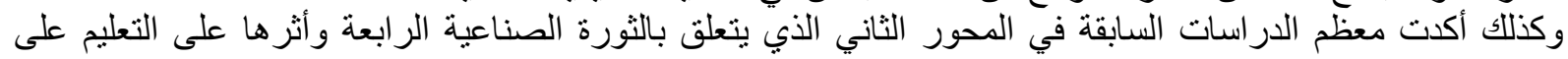

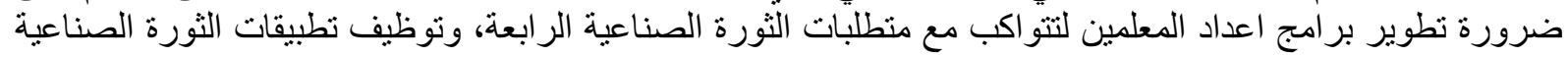

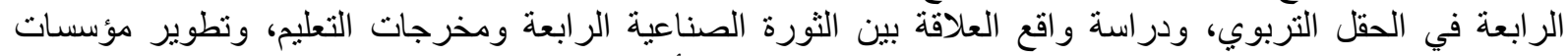

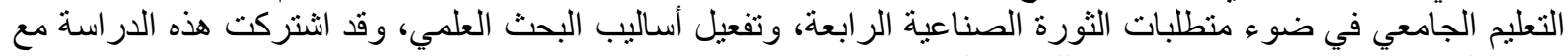
معظم الدراسات السابقة في استخدامها للمنهج الورة الوصفي.

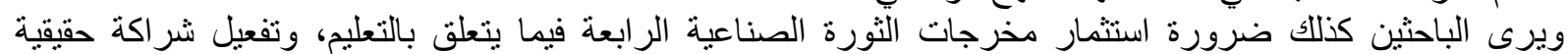

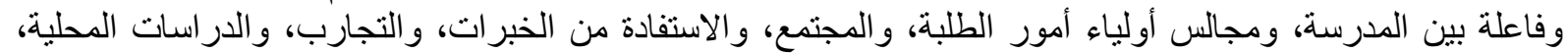
و الدولية، لمو اكبة التطور اتل العالية ولية في هذا المجال.

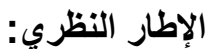
تضمن الإطار النظري للارراسة ثلاثة محاور، الأول تضمن الخبرات والتجاء التجارب الدولية لأدوار ومهام مجالس أولياء

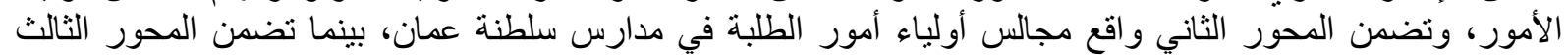

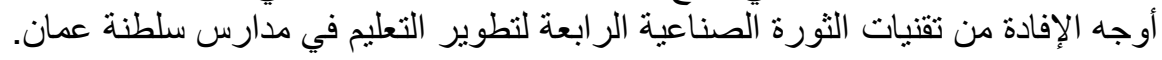

المحور الأول: الخبرات والتجارب الدولية لأدوار ومهام مجالس أولياء الأمور:

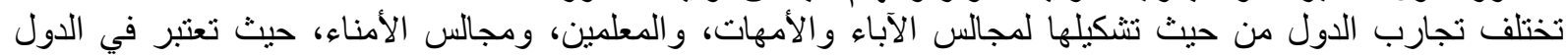

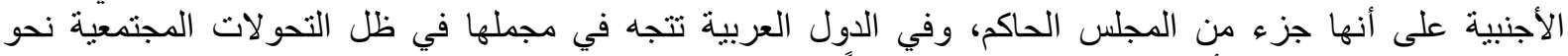

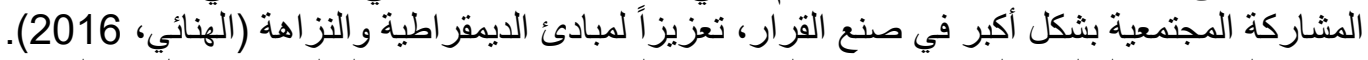

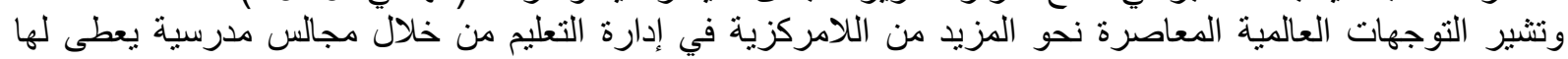

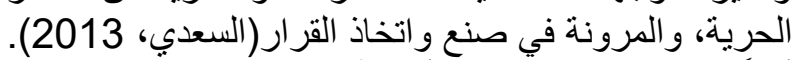
أولاً: تجارب بعض والمرنة في الدول الأجنبية:

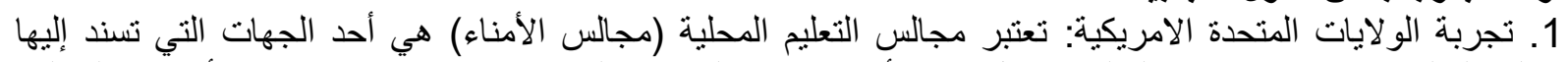

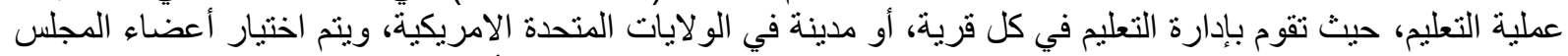

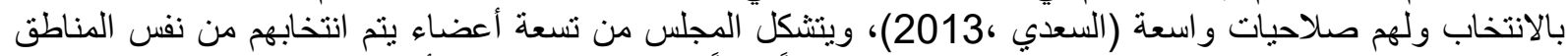

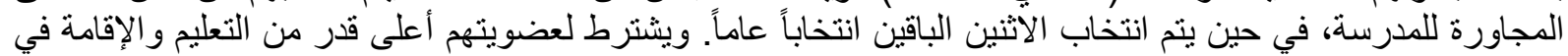

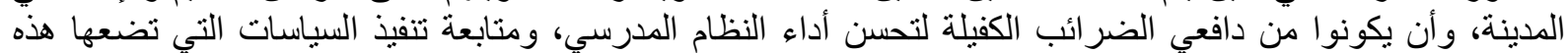

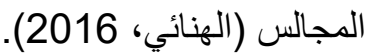

2.تجربة المملكة المتحدة (بريطانيا): يتشكل المجلس الحاكم بالمدرسة من هيئة منتخبة ومعتمدة من قبل السلطات التعليمية

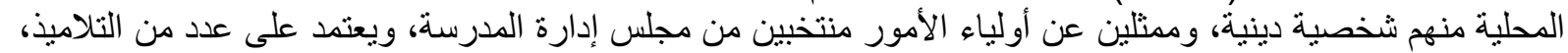

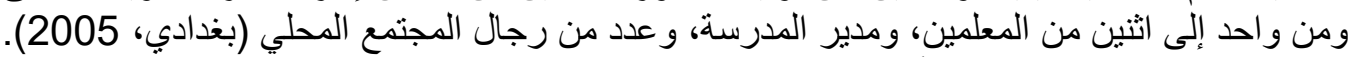

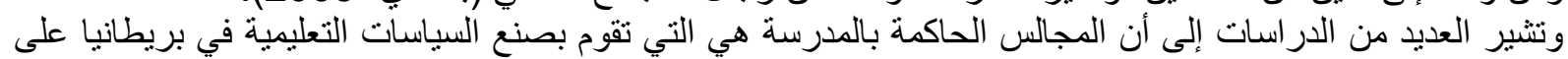

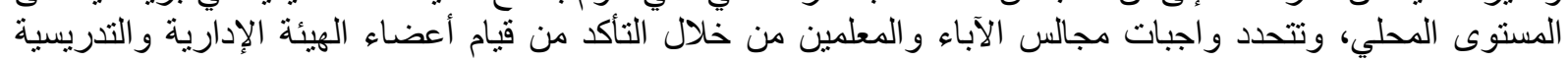

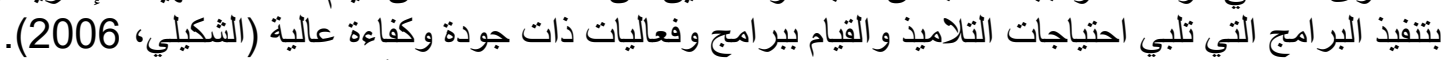

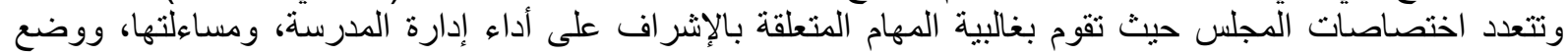

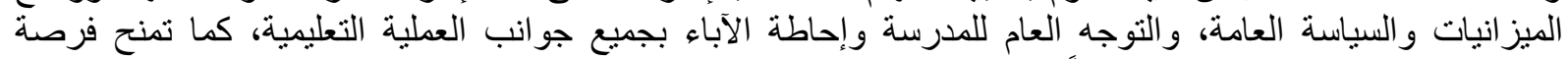

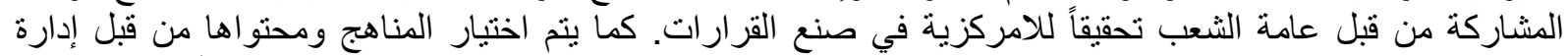

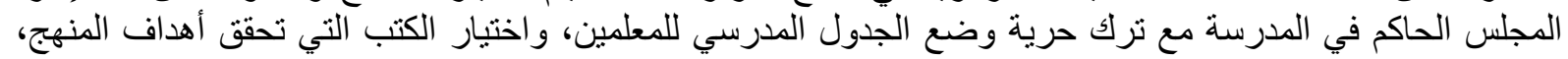

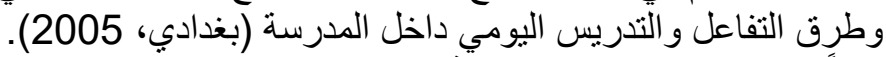

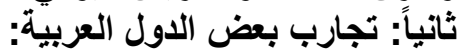

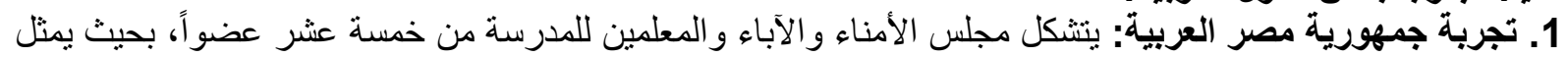

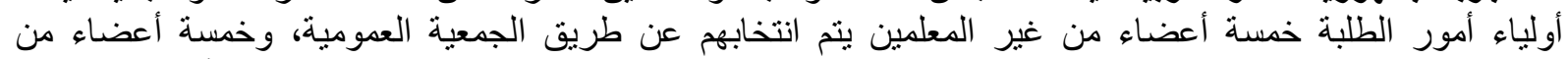

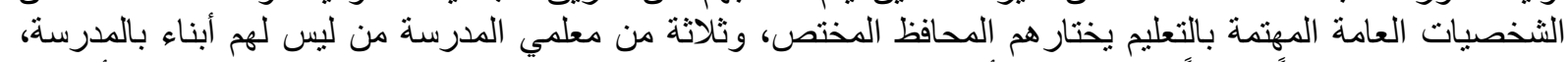

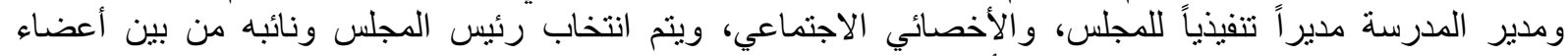

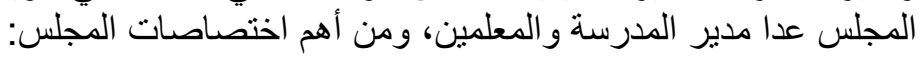

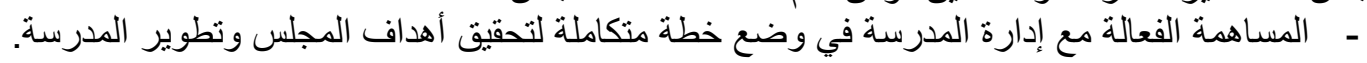




\section{DEVELOPING THE ROLES OF PARENTS' COUNCILS IN SCHOOLS IN THE SULTANATE OF OMAN IN THE LIGHT OF THE FOURTH INDUSTRIAL REVOLUTION}

ـ ـ العمل على دعم العملية التعليمية، وتطويرها، وتحديثها بمصادر تمويل غير تقليدية عن طريق تشجيع الجهود الذاتية للأفر اد ورجال الأعمال.

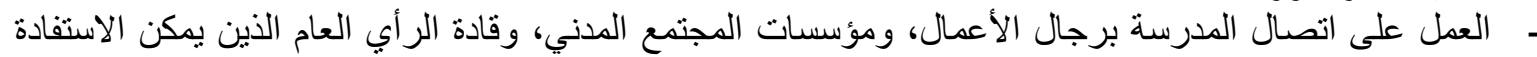
منهم. ـالتعاون مع إدارة المدرسة في وضع خطة تتفيذية لصيانة مر افق المدرسة.

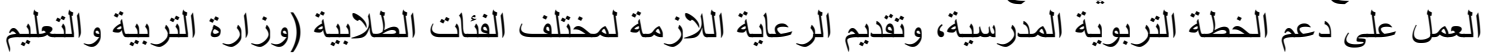
(2011،

2. تجربة دولة قطر: يتشكل المجلس في دولة قطر من أربعة أعضاء يمثلون أولياء أمور الطلبة، و عضو يمثل الموظفين

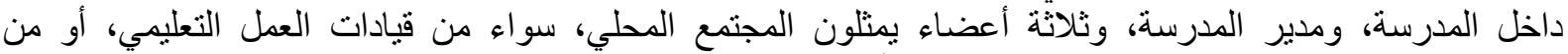

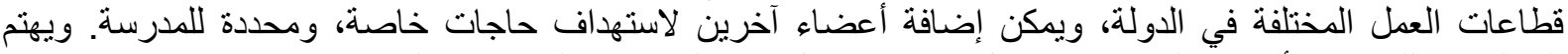

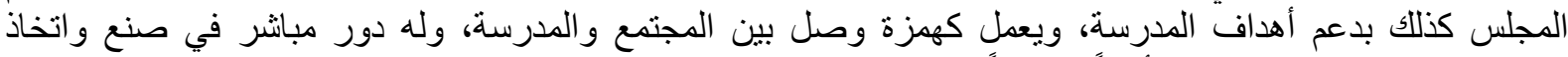
القرارات الرسمية التي تؤثر تأثثراً مباشراً في نجاح العملية التعليمية وتطوير ها، ودئ ودعم تفعيل المشاركة المجتمعية

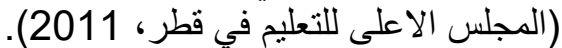

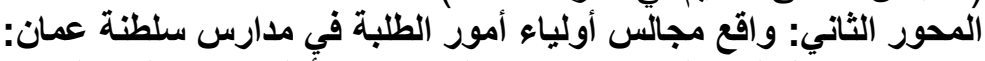

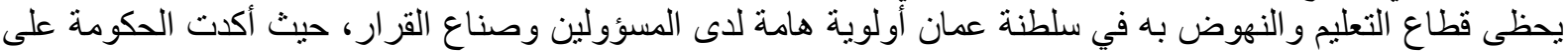

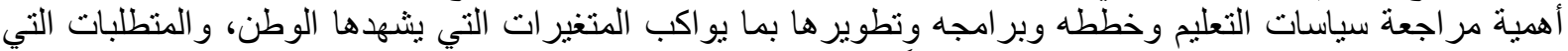

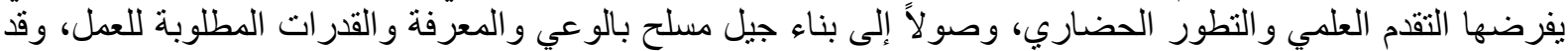

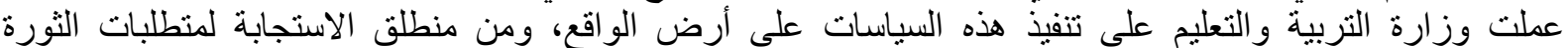

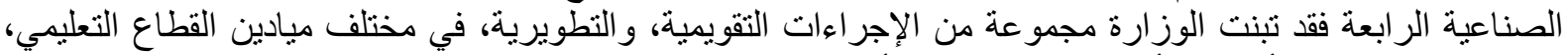

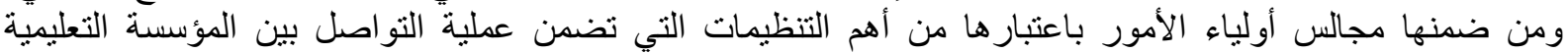

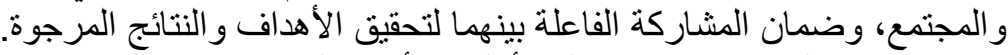

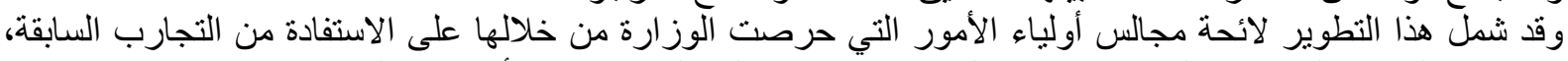

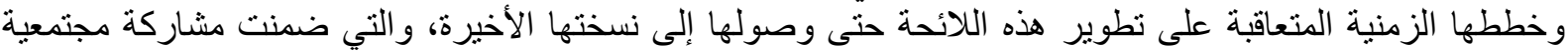

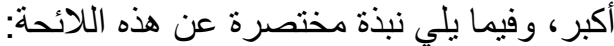

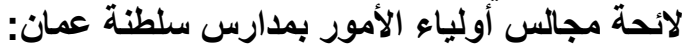

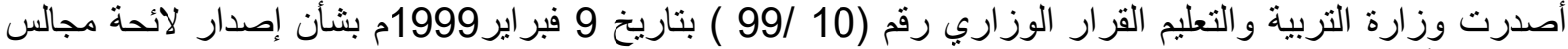

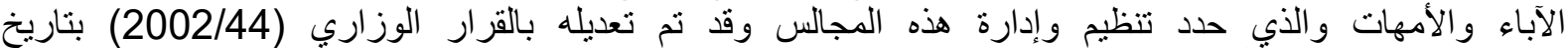

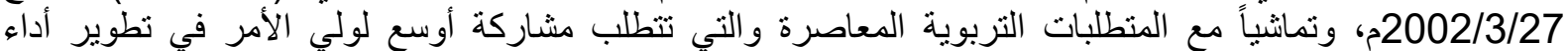

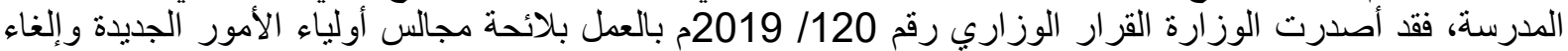

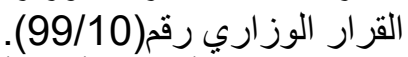
وتعتبر مجالس أولياء الأمور أبرز أبرز قنوات التوات التواصل في النظام التعليمي في سلطنة عمان، وهي كما تم تعريفها في لائحة

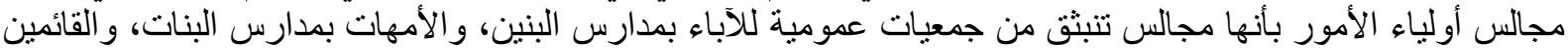

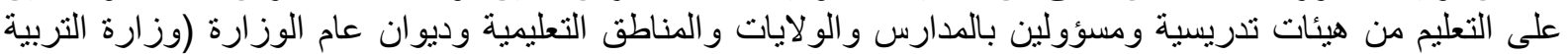

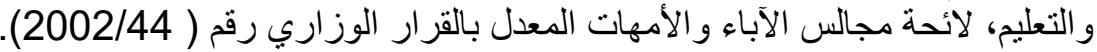

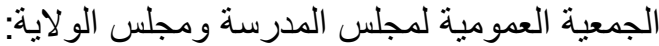

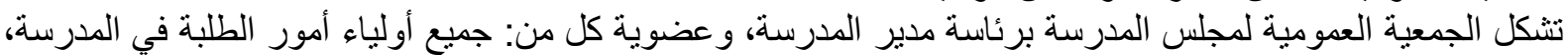
وجميع اعضاء الهيئة التدريسية، والوظائف المرتبطة بها، وممرض الصحة الصية المدرسية إن وجد ويكون مساعد المدير

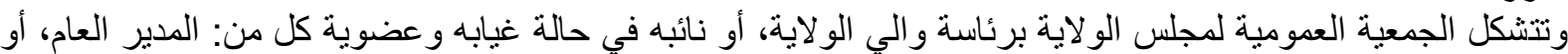

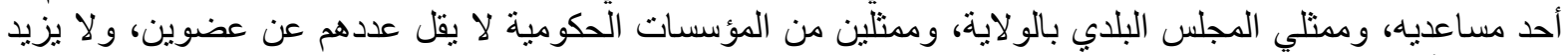

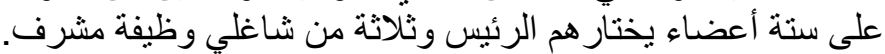

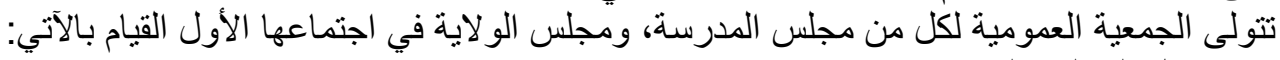

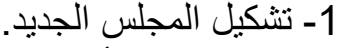

2- مناقثة تقرير أعمال المجلس السابق خلال الدئل الدورة السابقة. تصدر توصيات وقرار ات الجمعية العمومية لمجلس المدرسة، ومجلس الولاية بأغلبية أصوات الأعضاء الحاضرين. تثكيل مجلس المدرسة برئاسة أحد أولياء الأمور وعضوية كل من: 


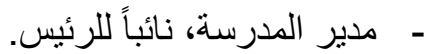

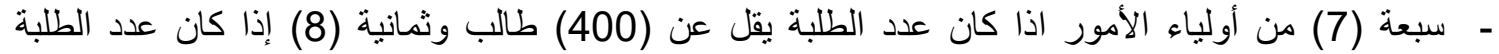

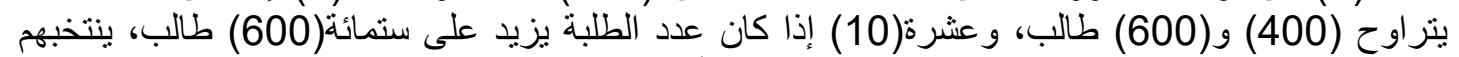

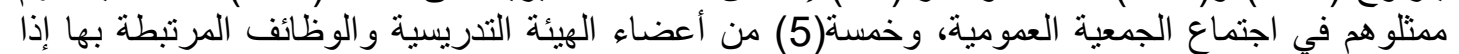

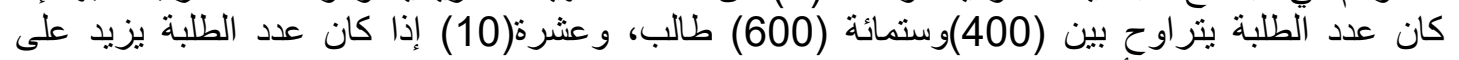

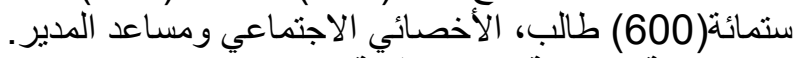

يتولى مجلس المدرسة ممارسة المهام الآتئة:

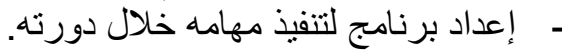

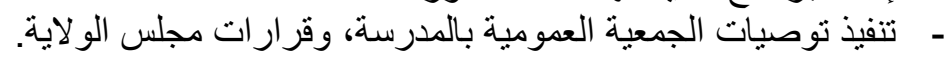

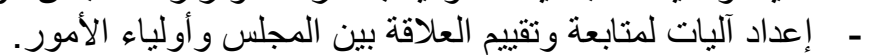

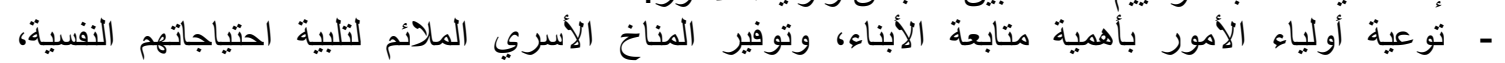
و الاجتماعية، و التربوية، و والصحية الصحية.

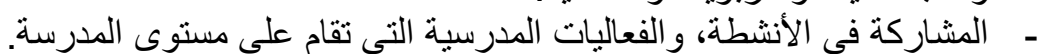

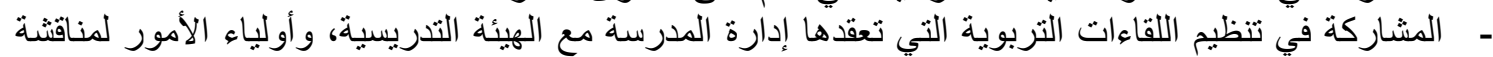

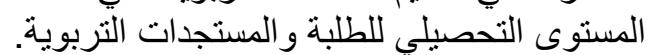

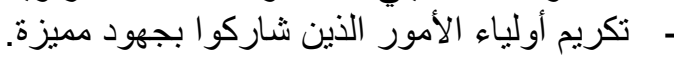

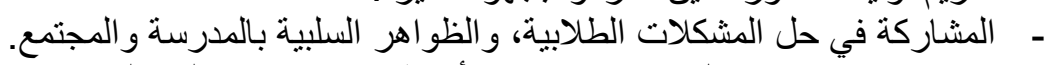

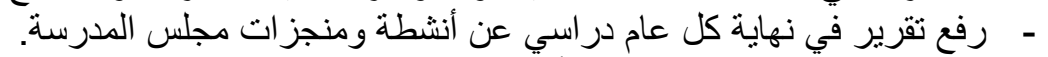

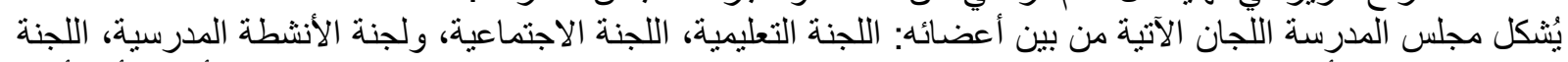

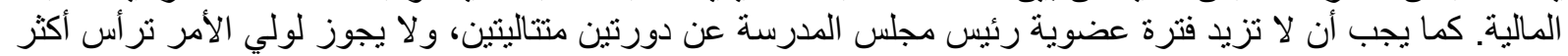
من مجلس مدرسة خلال دورة المجلس. يشكل مجلس الولاية برئاسنة والي الولاية أو من بنوب عنده الونه في حالة غيابه وعضوية كل من:

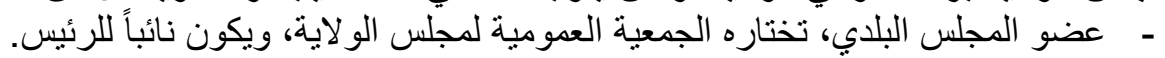

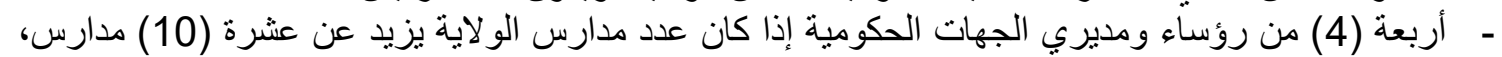

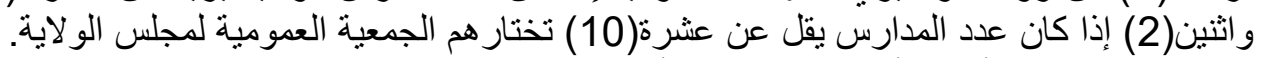

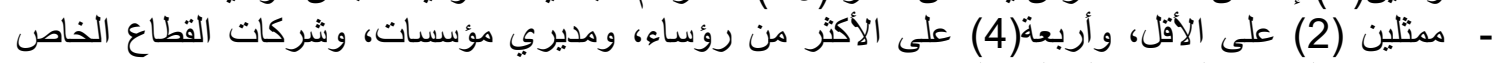

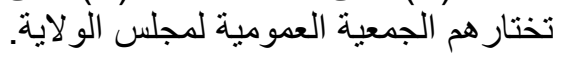

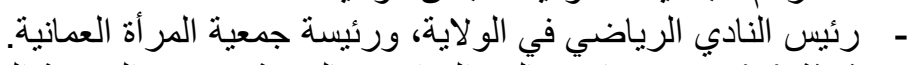

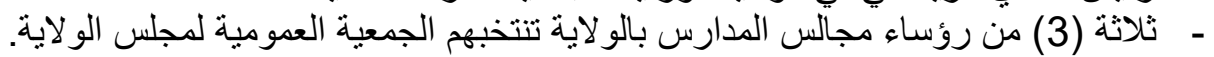

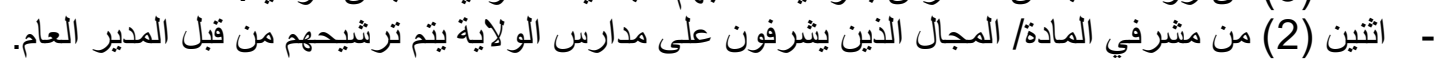

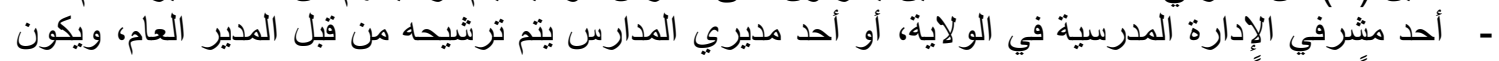

$$
\text { عضواً ومقرر اً. }
$$

\section{يتولى مجلس الولاية ممارسة المهام الآتية:}

1 1. تنفيذ نوصيات الجمعية العمومية بالو لاية.

2. توثيث التو اصل بين مجالس المدارس بالو لاية، والجية والجهات الحكومية والأهلية.

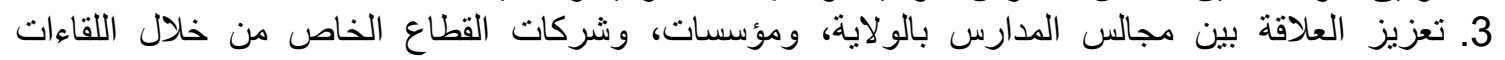
المختلفة. 4. تنفيذ زيار ات تبادلية مع مجالس المدارس. 5. المشاركة في تكريم الطنادية الطبة المجيدين في التحصيل الدراسي، والمجيدين من أعضاء الهيئة التدريسية، و الوظائف المرتبطة بها. 6. المشاركة في حل المشكلات الطلابية، و الظو اهر السلبية بالمدارس.

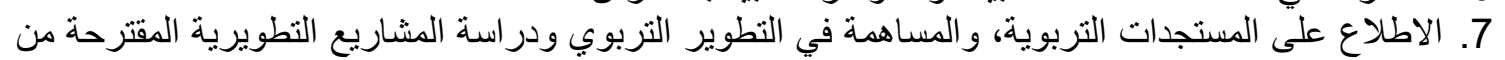
مجالس المدارس.

8. دراسة تقارير مجالس المدارس بالو لاية، و اتخاذ ما ير اه مناسباً بشأنها.

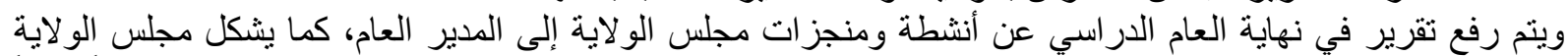

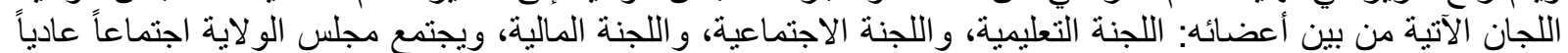

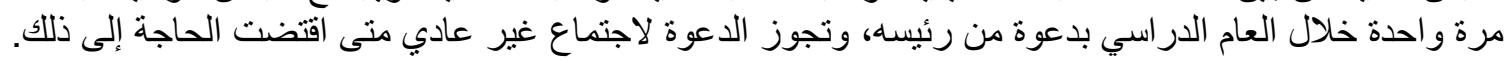
المحور الثالث: الاستفادة من تقنيات الثورة الصناعية الرابعة لتطوير التعليم في مدارس سلطنة عمان. 


\section{DEVELOPING THE ROLES OF PARENTS' COUNCILS IN SCHOOLS IN THE SULTANATE OF OMAN IN THE LIGHT OF THE FOURTH INDUSTRIAL REVOLUTION}

يُعد التعليم والتعلم، والبحث العلمي، واستثمار المواهب والقدرات الوطنية أهم الأولويات الوطنية التي وضعتها ولتهات رؤية

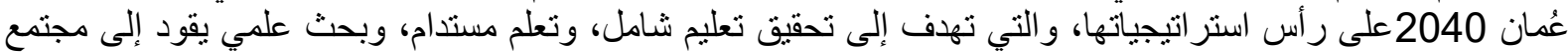
معرفي.

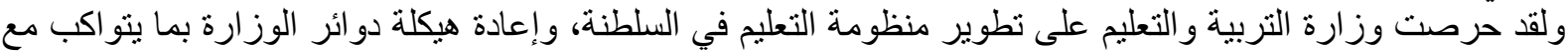

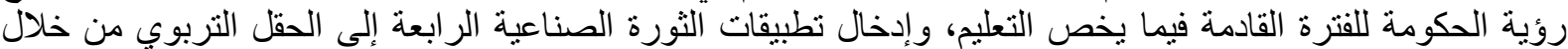

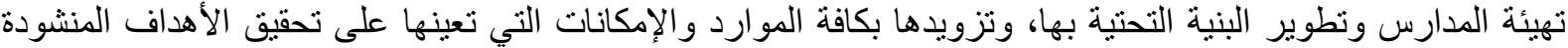

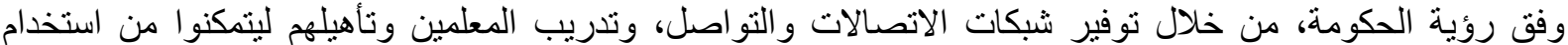

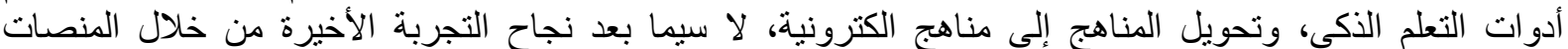

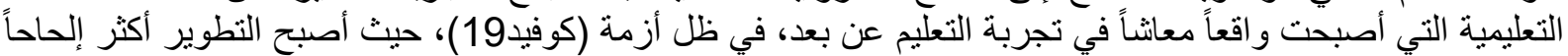
في مثل هذه الظروف التئ والأزمات.

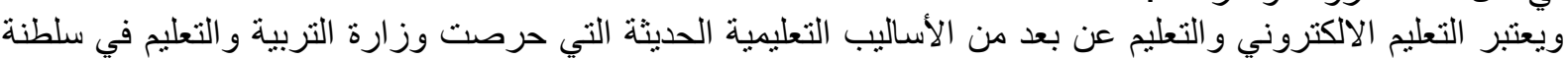

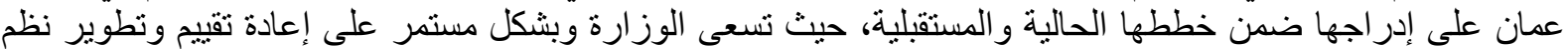

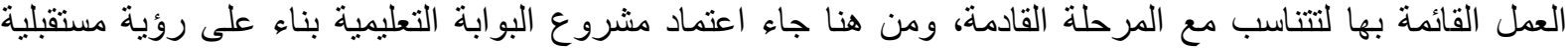

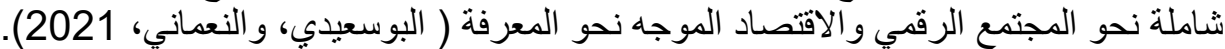

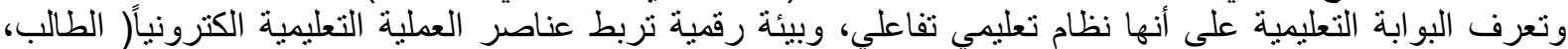

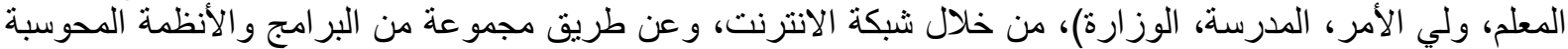

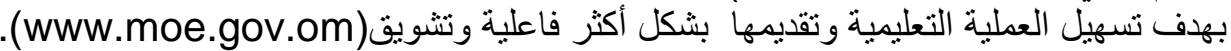

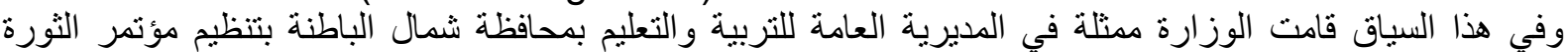

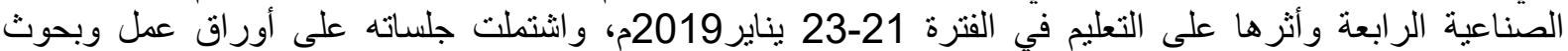

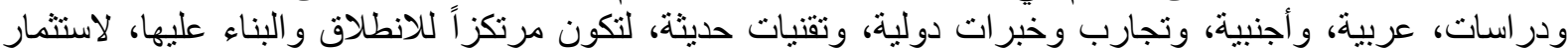
مخرجات الثورة الصناعية على قطاع التعلية فئية في السلطنة.

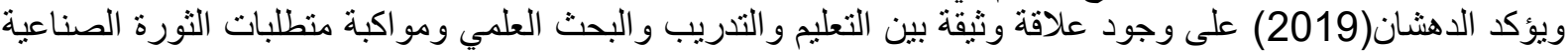

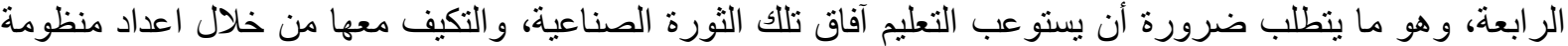

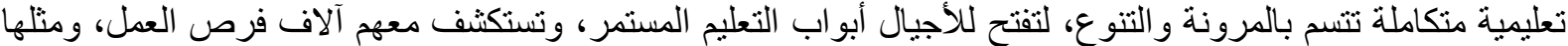

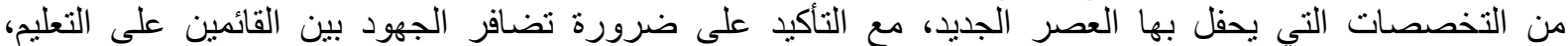
و العاملين في مجال تطوير التكنولوجيا، لتوظيف منتجاتهم لتخدم العملية التعليمية، وإضافة عنصري التشئية التشويق و الفضول لعناصر البيئة التعليمية. وقد انعكست الثورة الصناعية الرابعة وما جاءت باءئ من مستحدثات تكنولوجية على التعليم الذكي بصفة عامة، كما يشير ـ - توصيل المعلومات للطالب وأحتفاظه بالمعرفة المكتسبة وإعادة توظيفها و الاستفادة منها.

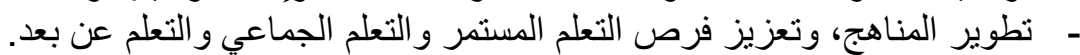

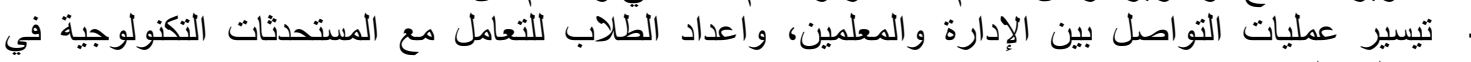
مختلف التخصصات.

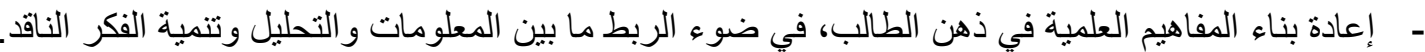

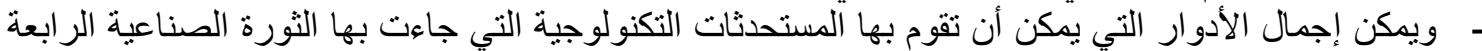

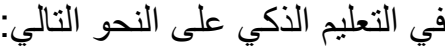

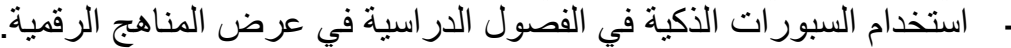

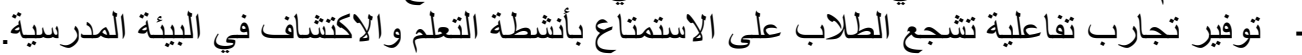

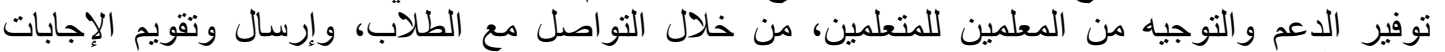
الكترونياً.

تقديم تجارب تعليمية جديدة و غير تقليدية، تعتمد على تطبيق الاستر اتيجيات الحديثة.

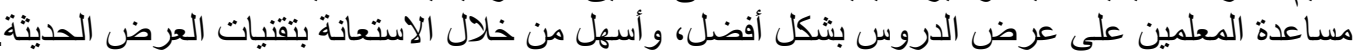
زيادة التفاعل بين أطراف العطلية التعليمية من الطلاب، و المعلمين، والإدارة، و أولياء الأمور بطريقة سهلة الطية ومنظمة.

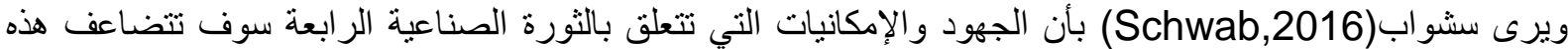

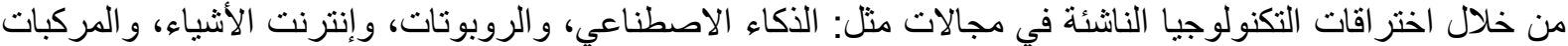

ذاتية التحكم، والطباعة ثلاثية الأبعاد، وتكنولوجيا النانو، و التكنولوجي الحيوية، وتخزين الطاقة، والروبة والحوسبة الكمومية). 
وقد أظهر تقرير مستقبل الوظائف والمهارات ( Future of jobs World Economic Forum,2018 (Survery

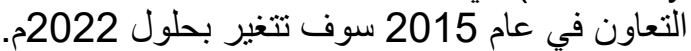

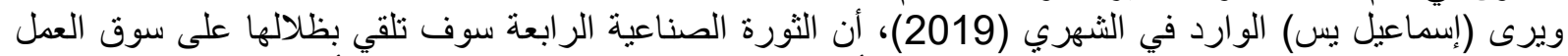

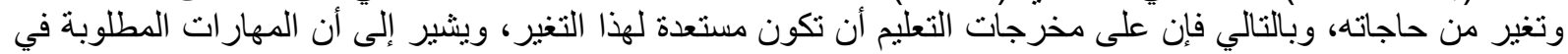

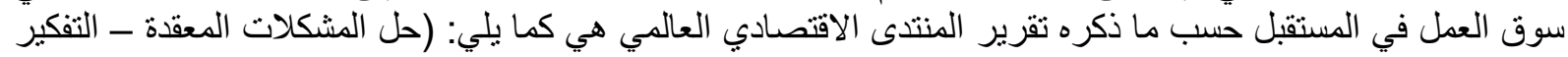

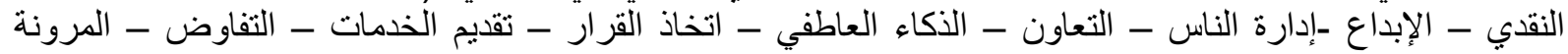
الإدر أكية).

وفي تقريز عن المهارات المطلوبة للثورة الصناعية الرابعة ( Mckinsey Global Institute,2018 )

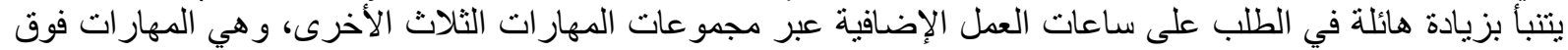

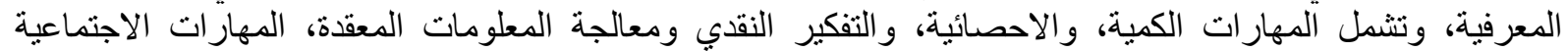

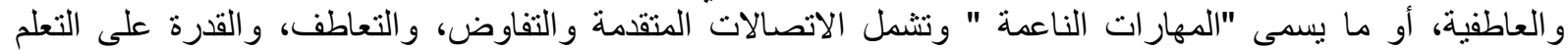

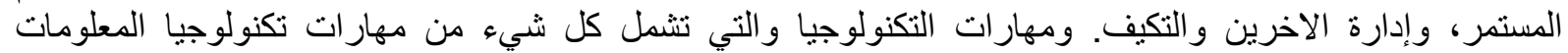

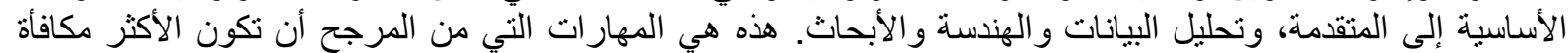

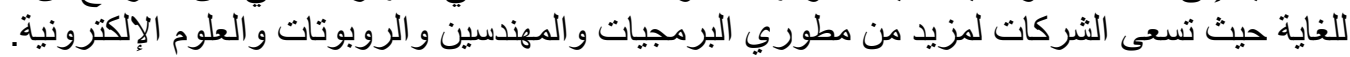

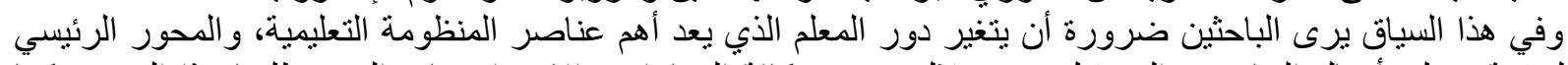

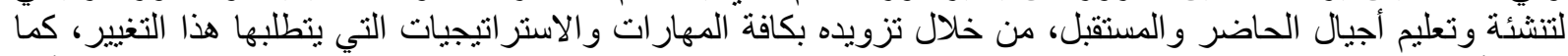

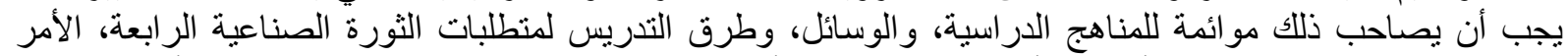

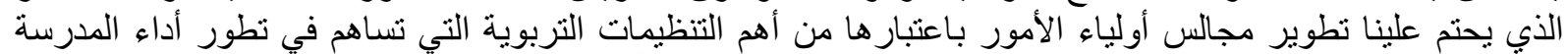

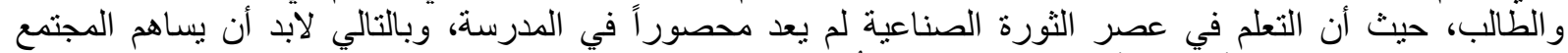

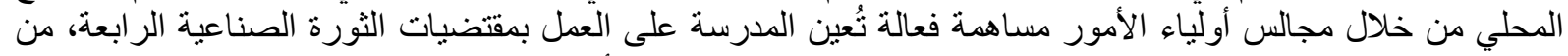

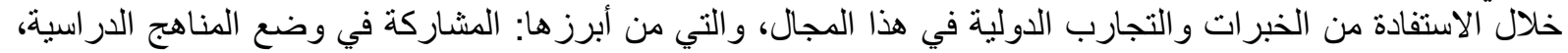

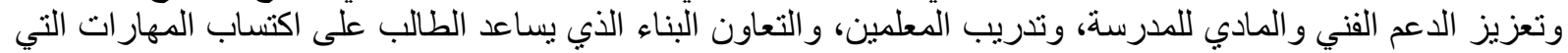
تتطلبها الثورة الصناعية الرعابعة.

التوصيات:

1- الاختيار الدقيق لأعضاء مجالس أولياء الأمور وفق آلية معينة تضمن اختيار الأعضاء الفاعلين في المجتمع.

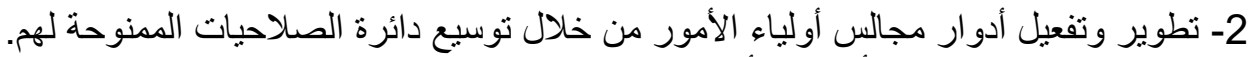

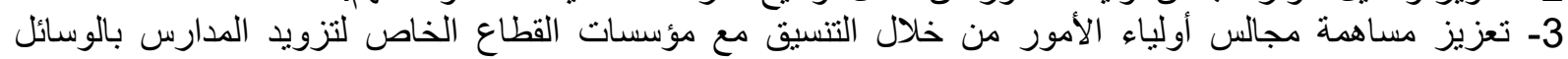

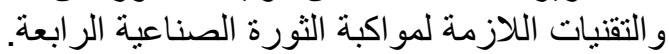

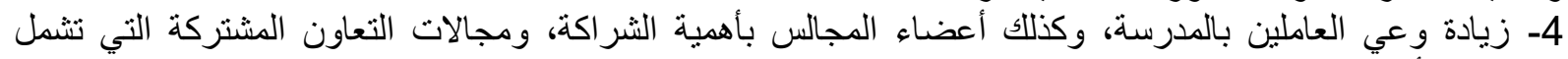

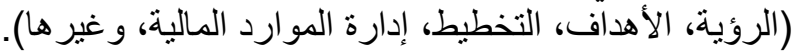

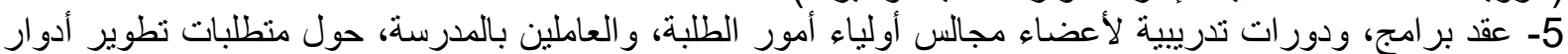

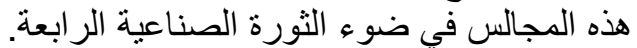

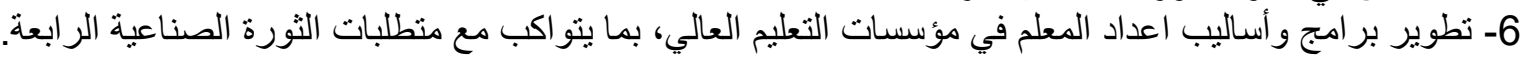

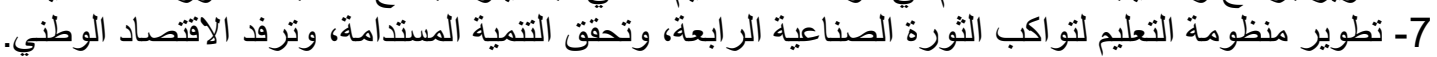

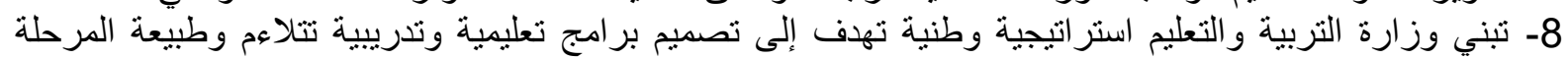

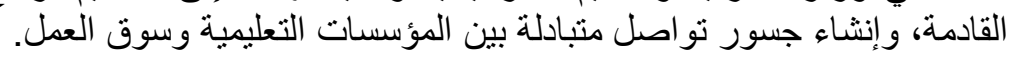
9- تزويد البيئة المدرسية بتقنيات، ومخرجات الثنورة الثناء الصناعية الرابعة، وتنمية وعي الطلبة بمنطلبات التعلم للمرحلة القادمة.

10- تبادل الخبرات والتجارب الدولية حول التوظيف الأمثل لتقنيات الثورة الصناعية الر ابعة في مجال التعليه.

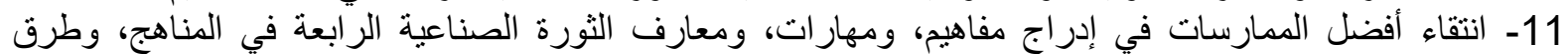
التدريس، وكافة الأنشطة التربوية.

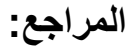

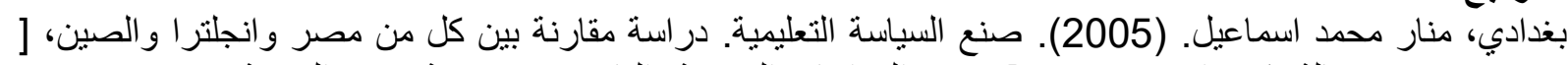
رسالة دكتور اه غير منشورة]، معهد الدراسات التربوية، القاهرة، جمهورية مصر التهر العربية. 


\section{DEVELOPING THE ROLES OF PARENTS' COUNCILS IN SCHOOLS IN THE \\ SULTANATE OF OMAN IN THE LIGHT OF THE FOURTH INDUSTRIAL \\ REVOLUTION}

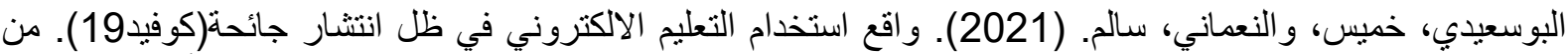

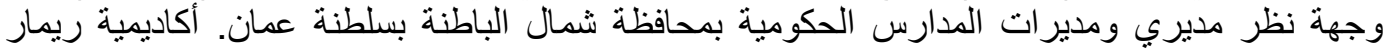

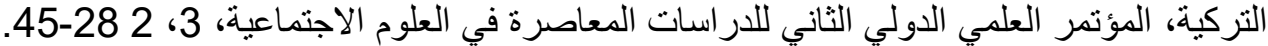

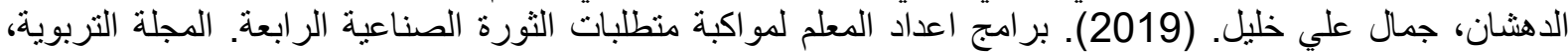
3153-3199 (68)

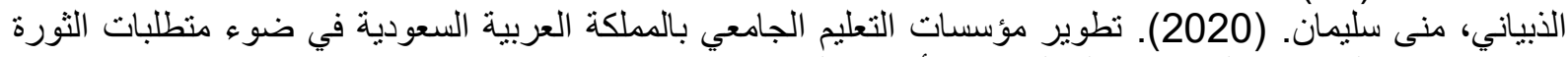

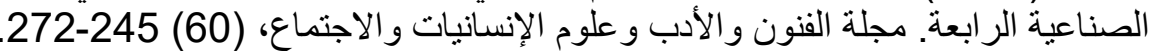

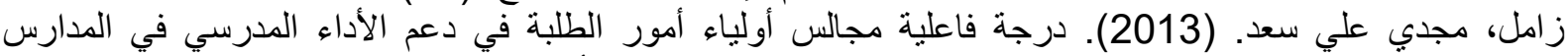

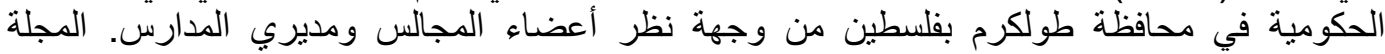

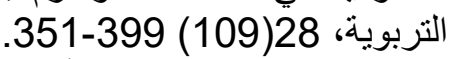

السعدي، خالد بن محمد. (2013). تطوير أداء مجالس الآباء و الأمهات في مدارس محافظة شمال الباطنة بسلطنة عمان

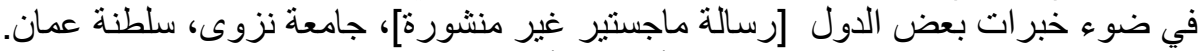

الثرفات، مسلم قاسم. (2019). درجة تفعيل مجالس أولياء الأمور و المعلمين في مدارس الثئلة البادية الثمالية الثرقية من

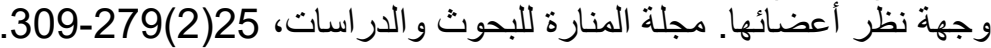

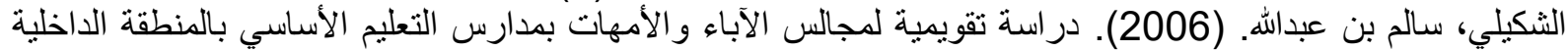

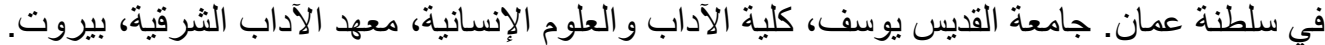

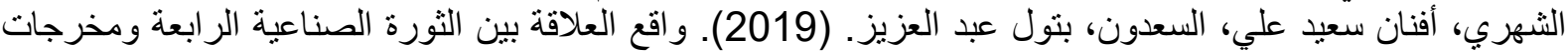

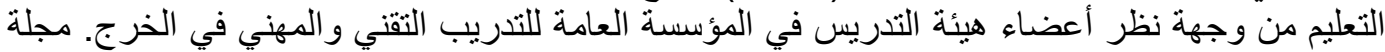

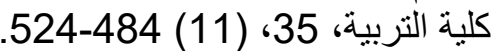

عاشور، محمد علي ذيب. (2010). دور مدير المدرسة فئة في تفعيل الثراكة بين المدرسة والمجتمع المحلي في سلطنة

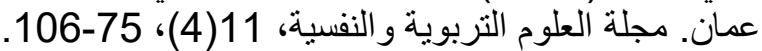

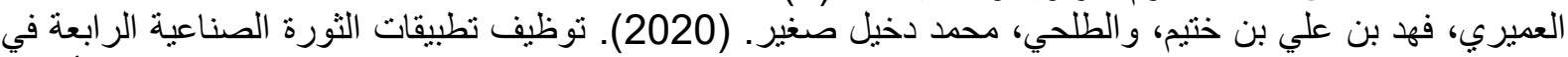
الجغرافيا التربوية بمراحل التعليم العام في المملكة العربية السعودية. مجلة جامعة التيفة فلسطين للأبحاث

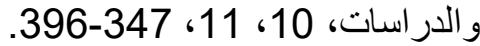

الفندي، ريما. (2016). دور مجالس أولياء الأمور في تفعيل العلاقة بين الأسرة والمدرسة من وجهة نظر معات معلمات

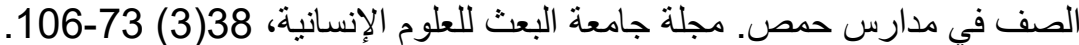

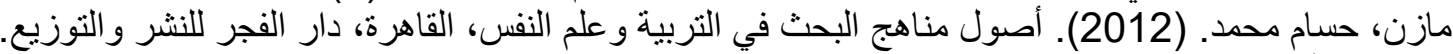

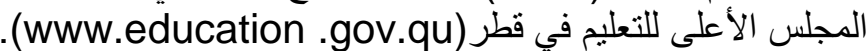
المجيني، أحمد بن عبداله بن علي. (2017). دور الإدارة المدرسية في تنمية علاقة المدرسة بالمجتمع المحلي في دالئي

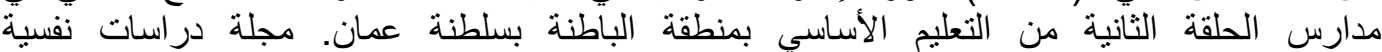
وتربوية،(19)، 2019)،

الهلالي، الثربيني. (2019). الثورة الصناعية الرابعة والتعليم الذكي. المجلة الدولية للتعليم بالانترنت، جمعية التنمية

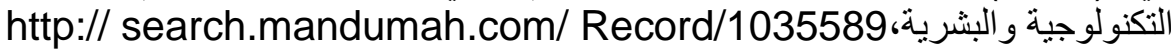

الهنائي، عبداله سعيد. (2016). فاعلية مجالس الآباء و الأمهات على مستوى و لايات محافظة الداخلية، والصعوبات التي تروي

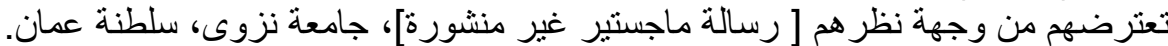

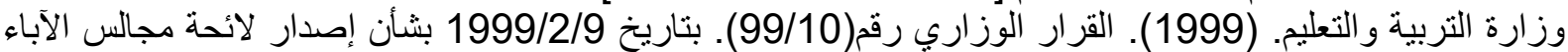

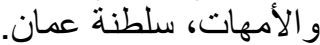

وزارة التربية والتعليم. (2002). لائحة مجالس الآباء والأمهات، مسقط، سلطنة عمان.

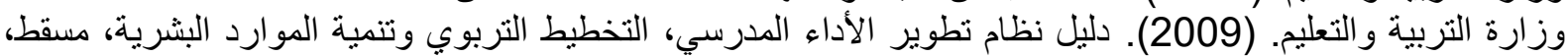
سلطنة عمان.

وزارة التربية والتعليم. (2011) ـ القرار الوزاري رقم (289). بتاريخ 2011/8/24م بشأن إعادة تنظيم مجالس الأمناء و الآباء و المعلمين، جمهورية مصر العربية.

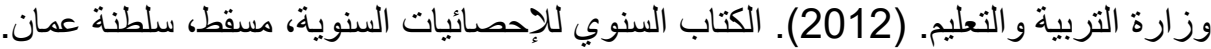

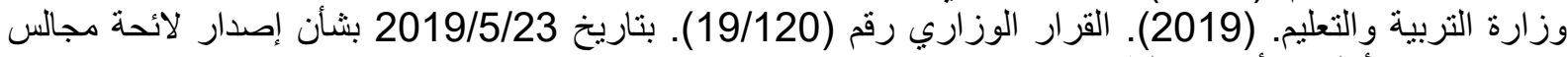
أولياء الأمور ، سلطنة عمان.

وز وارة التربية والتعليم، بوابة سلطنة عمان التعليمية Www.moe.gov.om 
Mckinsey Global Institute Discussion Paper.(2018).skill shift automation and future of work force.Retriered from Mckins \&Company Website.

Schwab, K. (2016). The Fourth Industrial Revolution. Retrieved from World Economic Forum. https://www.weform.org /about/ the -fourth-industrial-revolution-byklaus-schwab. 